ESPAÇO TEMÁTICO: TERRA, TERRITÓRIO E AMÉRICA LATINA

\title{
O acesso à terra no Brasil: reforma agrária e regularização fundiária
}

\author{
Fábio Luiz Zeneratti ${ }^{1}$ \\ https://orcid.org/0000-0001-5630-3180 \\ ${ }^{1}$ Universidade Federal da Fronteira Sul, Curso de Graduação Interdisciplinar em Educação do Campo, Laranjeiras do Sul, \\ PR, Brasil
}

\section{O acesso à terra no Brasil: reforma agrária e regularização fundiária}

Resumo: A pesquisa que sustenta este artigo teve como objetivo analisar as políticas de regularização fundiária e de reforma agrária no Brasil. O recorte temporal considerou os últimos 15 anos (2005-2020), hiato temporal capaz de evidenciar as continuidades, descontinuidades e relações entre as diferentes políticas fundiárias analisadas. Para isso, a metodologia de base documental apresentou-se como a mais adequada, pois permitiu avaliar dados e legislações referentes ao tema. Identificouse que no Brasil existe significativa relação entre os processos analisados: na medida em que se privilegia a regularização fundiária, deprecia-se qualquer política de reforma agrária.

Palavras-chave: Camponês. Regularização fundiária. Reforma agrária.

\section{The access to land in Brazil: land reform and regularization}

Abstract: The research in which this article is based on aimed to analyze land reform and regularization policies in Brazil. The period considered for the research covers the last 15 years (2005-2020), a time lapse able to evidence the continuities, discontinuities, and relationships amidst those policies. In this regard, the document-oriented methodology presented itself as the most accurate for this purpose since it allows the evaluation of data and legislation on the subject. As a result, it was understood that in Brazil there is a remarkable relationship between the processes of land reform and regularization: while the land regularization is preferred, any land reform policy is depreciated.

Keywords: Peasantry. Land regularization. Land reform.

Recebido em 23.02.2021. Aprovado em 15.05.2021. Revisado em 07.02.2021.

(c) (1) Este é um artigo publicado em acesso aberto (Open Access) sob a licença Creative Commons Attribution NonBY NC Commercial, que permite uso, distribuição e reprodução em qualquer meio, sem restrições desde que sem fins comerciais e que o trabalho original seja corretamente citado. 


\section{Introdução}

A formação territorial brasileira é marcada pela constituição da propriedade privada da terra em favor das elites rurais. Desde as Sesmarias, extintas somente em 1822, os privilégios à elite latifundiária começaram a ser gestados, uma vez que as terras eram cedidas segundo a capacidade de exploração de cada requerente (SILVA, 2008), ou seja, não bastava o seu prestígio político, o solicitante deveria apresentar capacidade financeira para explorar a terra segundo os parâmetros da época, o que se dava, basicamente, com o trabalho escravo - condições de que somente os abastados monetariamente dispunham.

A propriedade privada da terra encontrou guarida legal, pela primeira vez, na Constituição Imperial de 1824, chegando à sua plenitude com a Lei de Terras (Lei n. 601) em 1850. A terra tornada mercadoria, podendo ser comprada e vendida, encontrava-se em abundância no país nesse período ${ }^{1}$, evidentemente, para aqueles que podiam pagar por ela. Enquanto era garantido o estoque de terras às elites, os camponeses tiveram esse acesso bloqueado pelos parcos recursos de que dispunham para aplicar na compra de terra (MARTINS, 2010).

Nem mesmo os dispositivos legais promulgados na segunda metade do século XX foram capazes de mudar a lógica de acesso à terra. O Estatuto da Terra (Lei n. 4.504), de 1964, embora acenasse para a possibilidade de distribuição de terras aos camponeses, por meio da reforma agrária, tinha como prerrogativa central estimular a empresa rural, leia-se agricultura capitalista. Segundo Oliveira (1988), no que se refere à desconcentração fundiária, o Estatuto nasceu com o destino de nunca ser implementado.

Paradoxalmente, de certo modo, a previsão do conceito de função social da terra, presente no Estatuto da Terra e mantido na Constituição Federal de 1988, contribuiu para a luta contra o latifúndio, mas não alterou a dinâmica de apropriação das terras no país, movida pelo constante saque ao estoque de terras públicas. Nos últimos anos, sobretudo desde 2005, tais ações têm sido legitimadas por aportes legais em favor dos latifundiários, especialmente, validando a grilagem de terras.

Para Oliveira (2007, p. 66), a grilagem de terras revela o caminho "gratuito" do acesso à renda, ou seja, o bloqueio que a propriedade privada da terra exerce no modo de produção capitalista é removido pela apropriação ilegal. $\mathrm{O}$ grileiro se apodera de grandes extensões territoriais, cercando-as e requerendo-as para si, sem comprá-las nos cânones do mercado capitalista.

É neste contexto que as recentes medidas legais estão inseridas, trata-se de uma disputa histórica por terra (MOTTA, 2002). No cenário atual, assim como no passado, os latifundiários têm sido beneficiados, ao passo que os camponeses que não possuem terras veem a reforma agrária, enquanto política de governo, ser abandonada.

O objetivo desta pesquisa é justamente compreender essa dinâmica, isto é, tem por finalidade analisar a relação entre o favorecimento do acesso à terra aos latifundiários, por meio de políticas de regularização fundiária, e a paralisação da reforma agrária, fato que se expressa no abandono da política de criação de assentamentos rurais.

Para isso, foram analisados os dados da luta pela terra, de ocupações e da criação de assentamentos, bem como a legislação pertinente à regularização fundiária. Nesses termos, esta pesquisa tem como base os dados do Relatório DATALUTA Brasil, do Núcleo de Estudos, Pesquisas e Projetos de Reforma Agrária (NERA), e as legislações disponíveis sobre o tema nos portais digitais da Câmara dos Deputados e no Portal da Legislação do Planalto Federal.

Recorrer aos documentos permite a obtenção de materiais sem análises previamente elaboradas (CERVO; BERVIAN, 2002). No caso da legislação, ela permite a compreensão das intencionalidades pactuadas em cada ato legal. É sabido, como afirma Marés (2003), que somente as leis não são capazes de mudar a sociedade, mas, seguramente, elas expressam as mudanças em curso em determinada realidade social. Eis, aqui, as justificativas para essa escolha metodológica.

Por fim, acredita-se que a pesquisa apresentada neste artigo pode contribuir para a compreensão das dinâmicas territoriais em curso, para, assim, criar estratégias para transformá-las. Afinal, como nos ensina Lacoste (1988), é necessário pensar o espaço para nele saber combater.

\section{A luta pela terra no Brasil: o recuo na luta e a paralisação da reforma agrária}

Os números referentes às ocupações de terra no Brasil caíram significativamente nos últimos anos, chegando em 2019ao menor patamar desde a Constituição Federal de 1988. No Gráfico 1 são apresentados os números de ocupações por ano e permite a apreensão dessa variação. 
Gráfico 1 - Número de ocupações de terra no Brasil - 1988 a 2019 (Dados Comissão Pastoral da Terra)

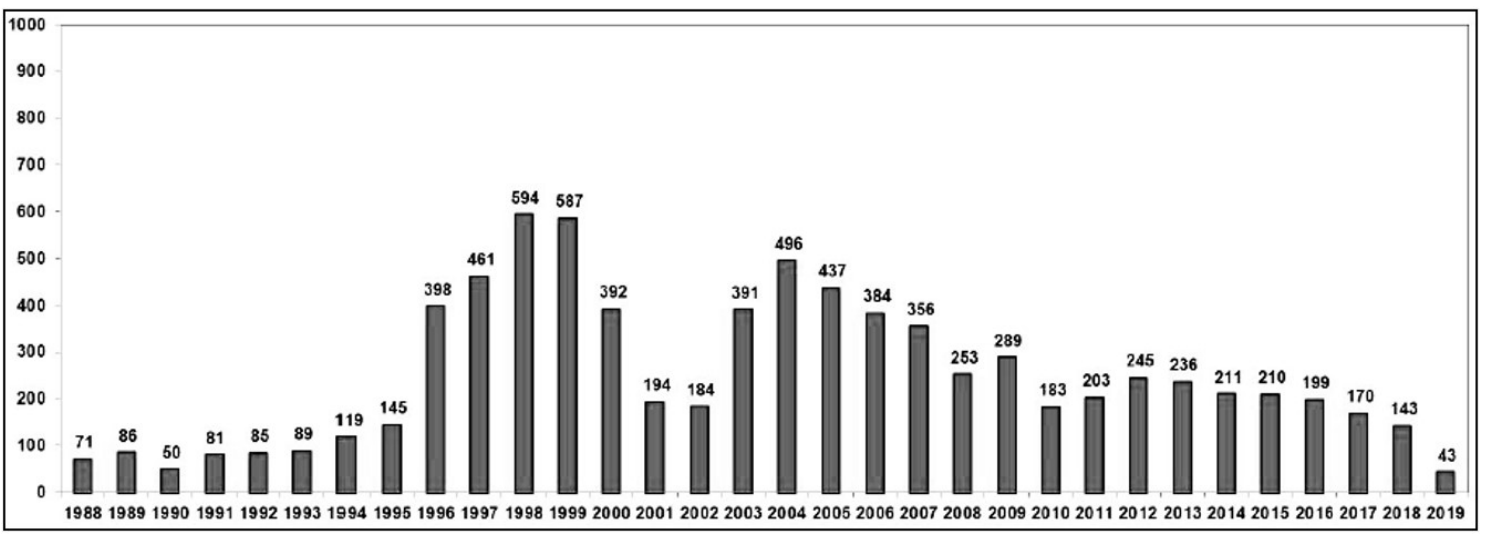

Fonte: Núcleo de Estudos, Pesquisas e Projetos de Reforma Agrária (2020, p. 13).

Um dado notável no Gráfico 1 é que no ano de 2019 foram apenas 43 ocupações de terra no país, o que representa uma redução de 69,9\% em relação ao ano de 2018. Redução ainda maior aconteceu no número de famílias envolvidas nessas ocupações, como pode ser observado no Gráfico 2. Nesse caso, em 2019, apenas 3.476 famílias participaram de ocupações de terra, representando uma redução de 79,6\% em relação a 2018 (NÚCLEO DE ESTUDOS, PESQUISAS E PROJETOS DE REFORMA AGRÁRIA, 2020).

Gráfico 2 - Número de famílias em ocupações de terra no Brasil - 1988 a 2019 (Dados Comissão Pastoral da Terra)

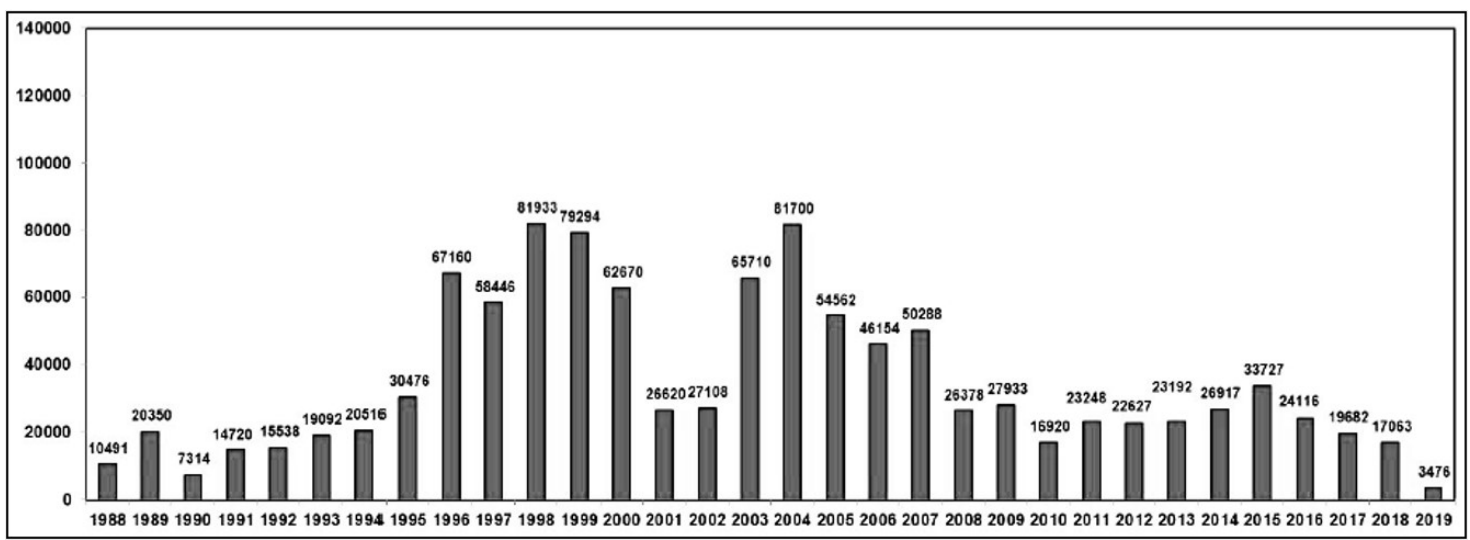

Fonte: Núcleo de Estudos, Pesquisas e Projetos de Reforma Agrária (2020, p. 13).

Esses dados demonstram um cenário de desmobilização social. Isso prejudica, certamente, a reforma agrária, pois, como destaca Fernandes (1996, p. 242) ao analisar os dados de assentamentos de reforma agrária no estado de São Paulo, em meados da década de 1990, 90\% das conquistas de terras resultaram das ações de ocupação de terras, o que permite inferir que a reforma agrária somente segue em pauta mediante luta social.

Tal desmobilização das lutas acontece, paradoxalmente, em um momento de ampliação da concentração fundiária. Sobre isso, Cosme (2020) afirma que o latifúndio ampliou seu domínio territorial no Brasil nos 
últimos anos. Tendo como base o intervalo entre o Censo Agropecuário de 2006 e o de 2017, nota-se que os estabelecimentos com área entre 1.000 hectares e menos de 2.500 hectares ganharam cerca de 17 milhões de hectares, o que representa aumento de 5\%. Ademais, Cosme (2020, p. 99) acrescenta que

[a] concentração fica mais explícita quando analisamos os extratos de menos de 10 ha e aqueles acima de 1.000 ha. Em 2006, os 50,34\% (2.477.151 milhões de unidades) do total geral dos estabelecimentos estavam enquadrados com menos de 10 ha, "espremidos" em apenas 2,34\% (7.798.777 milhões ha) da área total, enquanto os acima de 1.000 ha, representavam 0,97\% (47.578 mil unidades), monopolizando 45\% (150.143.096 milhões ha) das terras, ou seja, praticamente metade das terras agricultáveis. Em 2017, essa realidade praticamente não se alterou com relação aos pequenos estabelecimentos, mas com relação aos grandes, sim. Os estabelecimentos com menos de 10 ha correspondiam 50,91\% (2.543.681 milhões de unidades) com apenas 2,28\% (7.993.969 milhões ha) da área total, enquanto os acima de 1.000 ha, representavam 1,03\% (51.203 mil unidades), aumento o monopólio para 47,60\% (167.227.511 milhões ha).

Como se não bastasse a ampliação da concentração fundiária, no reverso da desmobilização social, a política de reforma agrária foi paralisada no despertar do mandato presidencial iniciado em 2019.

No Gráfico 3 é possível identificar que o presidente Jair Messias Bolsonaro (2019-2022) praticamente abandonou a criação de assentamentos rurais, visto que em 2019 foram criados apenas dois assentamentos.

Gráfico 3 - Número de assentamentos criados no Brasil - 1985 a 2019 (Dados INCRA)

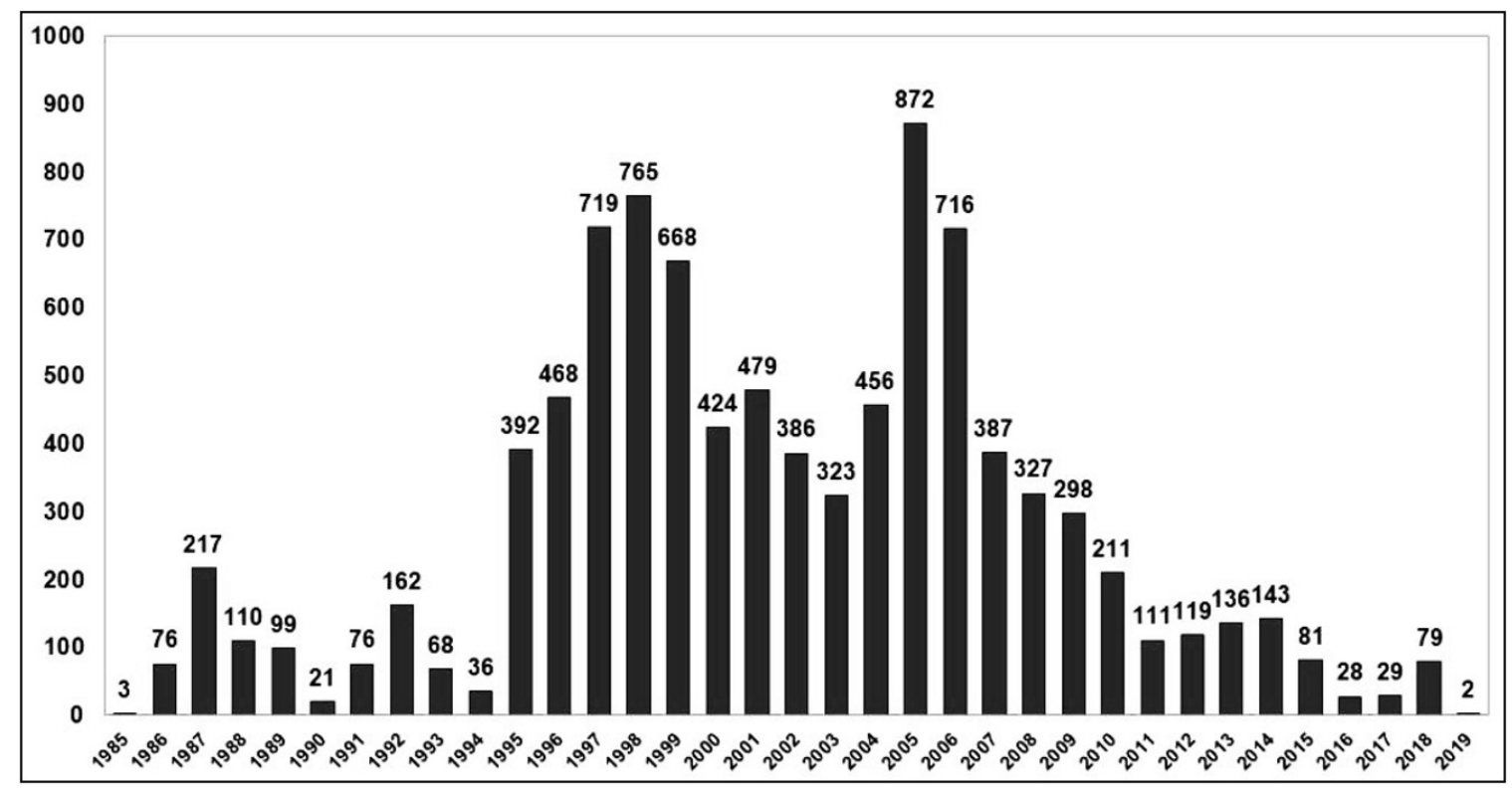

Fonte: Núcleo de Estudos, Pesquisas e Projetos de Reforma Agrária (2020, p. 13).

Sua antecessora, Dilma Rousseff, quando na Presidência da República, já não tinha a reforma agrária como prioridade, tanto que os números entre 2011 e 2016 são os menores do século XXI, sendo superados apenas pelos números do primeiro ano de Jair Bolsonaro e pelos resultados do curto mandato do ex-presidente Michel Temer, que governou o país entre 31 de agosto de 2016 e 31 de dezembro de 2018, logo após o golpe de Estado que levou ao impeachment de Dilma Rousseff (DANTAS; JABBOUR; SOBRAL, 2016). 
Em 2019, a redução na criação de assentamentos foi de 97,4\%, ou seja, não há atualmente qualquer política de criação de assentamentos rurais que possa, se não levar à desconcentração fundiária por completo, ao menos possibilitar o acesso à terra a uma fração dos camponeses (NÚCLEO DE ESTUDOS, PESQUISAS E PROJETOS DE REFORMA AGRÁRIA, 2020). Essa redução aparece, também, no número de famílias assentadas, como pode ser observado no Gráfico 4.

Gráfico 4 - Número de famílias assentadas no Brasil - 1985 a 2019 (Dados INCRA)

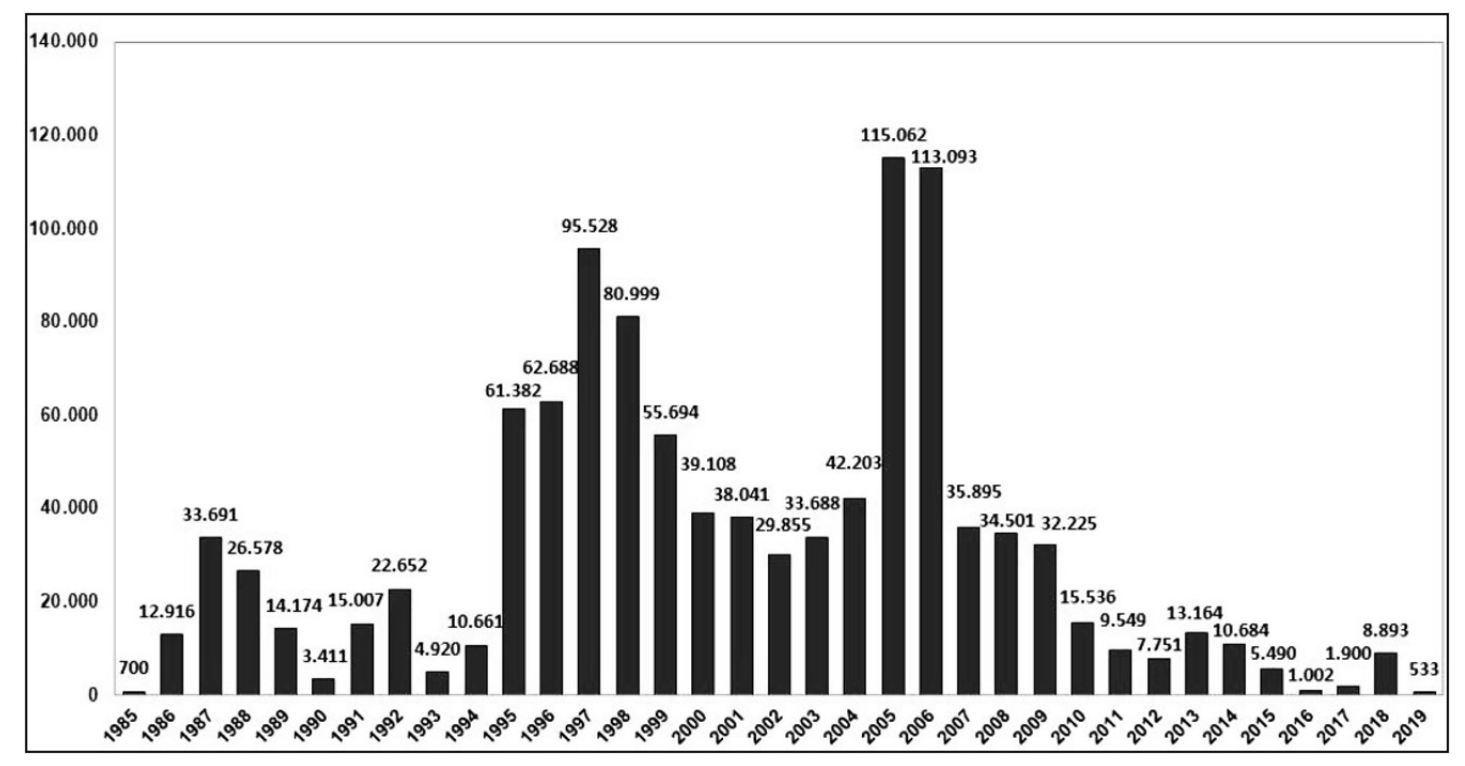

Fonte: Núcleo de Estudos, Pesquisas e Projetos de Reforma Agrária (2020, p. 13).

A queda no número de famílias assentadas, em 2019, foi de $94 \%$ em relação a 2018. Esses dados, em seu conjunto, podem revelar processos territoriais de escala temporal significativamente ampla (NÚCLEO DE ESTUDOS, PESQUISAS E PROJETOS DE REFORMA AGRÁRIA, 2020).

Nos últimos 15 anos, nota-se uma progressiva queda na luta pela terra, expressa no número de ocupações e de famílias envolvidas nelas. É a partir de 2005 que se verifica o início dessa queda, pois em 2004 foram 496 ocupações de terras, com 81.700 famílias envolvidas, enquanto no ano seguinte foram 437 ocupações e 54.562 famílias em ocupações de terras. Depois disso, o que se verificou foi a queda progressiva no número de ocupações e de famílias envolvidas, revelando o abandono da luta contra o latifúndio por meio da ocupação de terra como estratégia, até então muito utilizada pelos movimentos sociais do campo (FERNANDES, 1996), visto que tem como objetivo denunciar o não cumprimento da função social da terra e a grilagem.

Assim, na medida em que a luta pela terra enfraquece, a reforma agrária é paralisada. O ínfimo número de assentamentos criados em 2019, com apenas 533 famílias, é resultado do abandono da reforma agrária iniciado em 2006. Cabe destacar que em 2005 foram criados 872 assentamentos rurais e foram assentadas 115.062 famílias, os maiores números verificados desde 1985.

A partir de 2006, nota-se uma queda vertiginosa no número de assentamentos e famílias assentadas. Trata-se de um processo progressivo desde então, passando pelos mandatos presidenciais de Luiz Inácio Lula da Silva (2003-2010), Dilma Rousseff (2011-2016), Michel Temer (2016-2018) e culminando em 2019 com o quase abandono da reforma agrária pelo presidente Jair Bolsonaro.

Em síntese, os dados mostram que à medida que a luta pela terra diminui, a criação de assentamentos rurais por parte do governo federal passa a ser descontinuada. Esse fato evidencia que, no Brasil, a reforma agrária caminha a reboque da luta pela terra, isto é, sem luta não há terra para os camponeses. 


\section{Regularização fundiária: terra aos latifundiários e grileiros}

A segunda década do século XXI iniciou-se com indicativos de que a reforma agrária não será levada adiante a curto prazo, pelo menos é o que expressam os dados apresentados anteriormente. Como visto, ao passo que a disposição dos camponeses para lutar pela terra diminui, o Estado abandona a política de criação de assentamentos.

A partir do ano de 2019, a política fundiária brasileira adotou, basicamente, dois caminhos: a titulação das terras de assentamentos rurais, cuja análise não será apresentada neste artigo por exigir um trabalho à parte; e a regularização fundiária, que será analisada a seguir.

Parece retórica antiga dizer que a terra, no Brasil, está nas mãos de poucos. Aliás, todos os bancos de dados oficiais demonstram a extrema concentração fundiária no país. Segundo o Instituto Brasileiro de Geografia e Estatística (IBGE), a metade dos estabelecimentos rurais no Brasil $(50,91 \%)$ tem menos de 10 hectares, mas eles ocupam ínfimos 2,28\% da área dos estabelecimentos, cabendo aos grandes estabelecimentos, com mais de 1.000 hectares, ficarem com quase metade das terras disponíveis $(47,6 \%)$, mesmo sendo apenas $1,03 \%$ do número total de estabelecimentos (INSTITUTO BRASILEIRO DE GEOGRAFIA E ESTATÍSTICA, 2017).

Frente a essa situação, inclusive de ampliação do latifúndio, as medidas do atual governo têm ido na direção de aumentar o poder dos grandes proprietários de terras. O que não causa estranheza, visto que o presidente Bolsonaro venceu a disputa eleitoral, em 2018, pelo Partido Social Liberal (PSL), com o discurso de combater os movimentos populares ${ }^{2}$ e privilegiar os latifundiários.

Para isso, contribuem a Medida Provisória 910/2019 (MP 910/2019) e o Projeto de Lei 2.633/2020 (PL 2.633/2020), que tratam da regularização fundiária no Brasil. São mecanismos de transferência de terra pública para o domínio privado. Na Amazônia Legal, esse projeto de lei "ameaçaria pelo menos 19,6 milhões de hectares de áreas federais não destinadas" (BRITO, 2020, p. 01), o que equivale ao território do estado do Paraná.

A MP 910/2019, editada pela Presidência da República em dezembro de 2019, previa a regularização fundiária em terras da União, em todo o país, com área de até 2.500 hectares, ocupadas até maio de 2014. Ademais, previa a dispensa de assinatura dos confrontantes, aqueles que, porventura, se sentiriam atingidos pela regularização, bastando uma declaração do requerente dizendo que respeitou os limites da área requerida. Como se não bastasse, a prerrogativa de regularização era por autodeclaração para terras de até 15 módulos fiscais ${ }^{3}$, com dispensa de vistoria prévia em alguns casos. Essa MP não foi votada pela Câmara Federal e perdeu validade em maio de 2020. O relator do projeto na Câmara, o Deputado Federal Zé Silva (Solidariedade-MG), foi, então, o propositor do PL 2.633/2020.

Esse PL está, atualmente, em tramitação na Câmara Federal, com relatoria do Deputado Federal Marcelo Ramos (PL-AM). O PL 2.633/2020 mantém o conteúdo da MP 910/2019, ou seja, justifica-se sob afirmativa de "ampliar o alcance da regularização fundiária" (BRASIL, 2020). Territorialmente falando, isso significa a legitimação da grilagem de terras no Brasil.

Tal fato não constitui novidade, afinal, por mais que essas medidas tenham sido amplamente chamadas de MP e PL da grilagem ${ }^{4}$, não foram elas que inauguraram a prática da limitação da grilagem no Brasil. Atos semelhantes foram praticados sem parcimônia pelos governos anteriores. O Quadro 1 contribui para esse entendimento.

Observa-se, ao longo dos períodos presidenciais, a preocupação com as políticas de regularização de latifúndios, basicamente postas em prática sob a premissa de regularização de pequenas posses camponesas na Amazônia (OLIVEIRA, 2009). É isso o que expressam a MP 442/2008 e a Lei 11.762/2009, promulgadas durante o governo Lula, que chegou ao poder em 2003 por meio do Partido dos Trabalhadores (PT), empunhando a bandeira em defesa das pautas populares, entre elas a reforma agrária (FERNANDES, 2003).

Paradoxalmente, tais medidas, promulgadas durante o governo dos trabalhadores, permitiram a legalização de cerca de 67 milhões de hectares de terras públicas, a maior parte ocupada por grileiros, como assevera Paulino (2011, p. 114). Essas medidas possibilitaram a regularização de posses com até 15 módulos fiscais na Amazônia. Isso permite a legalização de áreas do patrimônio público de até 1.500 hectares. Para Oliveira (2009), não resta dúvida: é a legalização da grilagem de terras no Brasil.

Na Amazônia Legal, as terras cadastradas com a designação equivocada de "posse" somam 297,9 mil imóveis. Desse total, 62,3 mil imóveis, classificados como médias e grandes propriedades, não poderiam ser legitimados de acordo com a legislação vigente. Eles ocupam uma área de 35,6 milhões de hectares [...] e que até a chamada Medida Provisória do Bem e a MP 422/08 não poderiam ser legitimados. Assim, são as pequenas propriedades que vão justificar a legitimação da grilagem dos médios e grandes imóveis. (OLIVEIRA, 2009, p. 01). 
Quadro 1 - A política de regularização fundiária no Brasil - 2008 a 2020

\begin{tabular}{|c|c|c|c|c|c|}
\hline $\begin{array}{l}\text { Medida } \\
\text { Provisória }\end{array}$ & Presidente & Lei & Área & Abrangência & $\begin{array}{l}\text { Informações } \\
\text { adicionais }\end{array}$ \\
\hline MP 422/2008 & Lula & $\begin{array}{c}\text { Tornou-se a Lei } \\
11.763 / 2008 \text { (com a } \\
\text { mesma redação da MP) }\end{array}$ & $\begin{array}{c}\text { Até } 15 \\
\text { módulos fiscais } \\
\text { (1.650 hectares) }\end{array}$ & Amazônia Legal & - \\
\hline \multirow[t]{2}{*}{ MP 458/2009 } & \multirow{2}{*}{ Lula } & \multirow{2}{*}{$\begin{array}{c}\text { Tornou-se a Lei } \\
11.952 / 2009\end{array}$} & \multirow{2}{*}{$\begin{array}{c}\text { Até } 15 \\
\text { módulos fiscais } \\
\text { (1.650 hectares) }\end{array}$} & \multirow{2}{*}{ Amazônia Legal } & $\begin{array}{l}\text { - Áreas ocupadas até } \\
\text { dezembro de 2004; }\end{array}$ \\
\hline & & & & & $\begin{array}{l}\text { - Deu origem ao } \\
\text { Programa Terra Legal. }\end{array}$ \\
\hline \multirow{3}{*}{ - } & \multirow{3}{*}{ Lula } & \multirow{3}{*}{ Lei $11.952 / 2009$} & \multirow{3}{*}{$\begin{array}{l}\text { Até } 15 \text { módulos } \\
\text { fiscais e não } \\
\text { superiores a } 1.500 \\
\text { hectares }\end{array}$} & \multirow{3}{*}{ Amazônia Legal } & $\begin{array}{l}\text { - Áreas ocupadas até } \\
\text { julho de 2008; }\end{array}$ \\
\hline & & & & & $\begin{array}{c}\text { - Prazo de renegociação } \\
\text { de dívidas em atraso: } \\
\text { até } 2012 ;\end{array}$ \\
\hline & & & & & $\begin{array}{c}\text { - Trata-se da principal } \\
\text { lei sobre o tema, todas } \\
\text { as posteriores são para } \\
\text { alterá-la, ampliando seu } \\
\text { alcance. }\end{array}$ \\
\hline \multirow[t]{4}{*}{ MP 759/2016 } & Temer & $\begin{array}{c}\text { Tornou-se a Lei } \\
13.465 / 2017\end{array}$ & $\begin{array}{l}\text { Até } 15 \text { módulos } \\
\text { fiscais e não } \\
\text { superiores a } 1.500 \\
\text { hectares }\end{array}$ & $\begin{array}{l}\text { Brasil: mas } \\
\text { somente em } \\
\text { terras do } \\
\text { INCRA. }\end{array}$ & $\begin{array}{c}\text { - Áreas ocupadas até } \\
2014 .\end{array}$ \\
\hline & \multirow{3}{*}{ Temer } & \multirow{3}{*}{ Lei $13.465 / 2017$} & \multirow{3}{*}{$\begin{array}{c}\text { Áreas não } \\
\text { superiores a } \\
2.500 \text { hectares } \\
\text { (22 módulos fiscais) }\end{array}$} & \multirow{3}{*}{$\begin{array}{l}\text { Brasil: mas, } \\
\text { somente em } \\
\text { terras do INCRA }\end{array}$} & $\begin{array}{l}\text { - Áreas ocupadas até } \\
\text { julho de 2008; }\end{array}$ \\
\hline & & & & & $\begin{array}{c}\text { - Essa lei altera a Lei } \\
\text { 11.952/2009; }\end{array}$ \\
\hline & & & & & $\begin{array}{l}\text { - Extensão de prazo de } \\
\text { renegociação para } 2021 .\end{array}$ \\
\hline \multirow{3}{*}{ MP 910/2019 } & \multirow{3}{*}{ Bolsonaro } & \multirow{3}{*}{$\begin{array}{c}\text { Tornou-se o PL } \\
2.633 / 2020\end{array}$} & \multirow{3}{*}{$\begin{array}{l}\text { Até } 2.500 \text { hectares } \\
\text { ( } 22 \text { módulos } \\
\text { fiscais) }\end{array}$} & \multirow{3}{*}{$\begin{array}{c}\text { Brasil: agora em } \\
\text { todas as terras da } \\
\text { União }\end{array}$} & $\begin{array}{l}\text { - Áreas ocupadas até } \\
\text { maio de 2014; }\end{array}$ \\
\hline & & & & & $\begin{array}{l}\text { - Dispensa de assinaturas } \\
\text { dos confrontantes, basta } \\
\text { uma declaração do } \\
\text { requerente dizendo que } \\
\text { respeitou os limites; }\end{array}$ \\
\hline & & & & & $\begin{array}{l}\text { - Regularização por } \\
\text { autodeclaração para } \\
\text { terras de até } 15 \text { módulos } \\
\text { fiscais no Brasil. }\end{array}$ \\
\hline \multirow{3}{*}{-} & \multirow{3}{*}{ Bolsonaro } & \multirow{3}{*}{ PL 2.633/2020 } & \multirow{3}{*}{$\begin{array}{l}\text { Até } 2.500 \text { hectares } \\
\text { (22 módulos } \\
\text { fiscais })\end{array}$} & \multirow{3}{*}{$\begin{array}{l}\text { Brasil: em todas } \\
\text { as terras da } \\
\text { União }\end{array}$} & $\begin{array}{l}\text { - Áreas ocupadas até } \\
\text { julho de 2008; }\end{array}$ \\
\hline & & & & & $\begin{array}{l}\text { - Projeto de Lei, ainda } \\
\text { não foi votado; }\end{array}$ \\
\hline & & & & & $\begin{array}{l}\text { - Extensão de prazo de } \\
\text { renegociação para } 2024 .\end{array}$ \\
\hline
\end{tabular}

Fonte: Adaptado de BRASIL (2021). 
O autor destaca, ainda, que a ocupação de terras devolutas da União é regulada pela Lei 6.383/76, que caracteriza como ocupante a família que estabeleça moradia e tenha tornado produtivas com seu trabalho área de terra contínua de até 100 hectares, desde que não seja proprietária de imóvel rural ou urbano. Oliveira (2009) também afirma que essa legislação continua sendo utilizada pelo Instituto Nacional de Colonização e Reforma Agrária (INCRA) para arbitrar sobre a regularização, muito embora a Constituição Federal de 1988 determine o limite da posse em 50 hectares, com ocupação de cinco anos ininterruptos. Seja em um caso ou no outro, trata-se de pequenas propriedades.

Considerando o período analisando, somente a ex-presidenta Dilma Rousseff não promulgou atos legais favorecendo, ou ampliando, o acesso ao patrimônio fundiário nacional, o que foi resolvido em benefício dos grileiros em meados de 2016, quando a Presidência da República foi tomada pelo ex-vice-presidente Michel Temer. Em pouco mais de três meses na cadeira presidencial, é promulgada por ele a MP 759/2016, ampliando a regularização fundiária por todo o território nacional, desde que em terras do INCRA. Antes disso, somente terras da União localizadas na Amazônia Legal eram passíveis de regularização.

O golpe de Estado, que resultou no impeachment da ex-presidenta eleita Dilma Rousseff (DANTAS; JABBOUR; SOBRAL, 2016, p. 33), tornou ainda mais frágeis as pautas populares, desfavor que, certamente, não aconteceu para as elites nacionais. Em 2017, o ex-presidente Temer sancionou a Lei n. 13.465/2017, que altera a Lei n. 11.952/2009, do ex-presidente Lula, estendendo o prazo de renegociação das terras adquiridas e não pagas (de 2012 para 2021), bem como ampliando a dimensão das terras passíveis de desapropriação (de 1.500 para 2.500 hectares) e alargando a abrangência da política de regularização fundiária - antes somente na Amazônia Legal, depois no Brasil todo em terras do INCRA.

A Lei n. 11.952/2009 está em vigência atualmente, com modificações realizadas ao longo do tempo. Nela, estão previstas duas modalidades de regularização fundiária. A primeira se refere às áreas ocupadas até julho de 2008. Nesse caso, os imóveis com até um módulo fiscal podem ser regularizados gratuitamente, já os imóveis de um módulo fiscal a 2.500 hectares poderão ser regularizados mediante pagamento à União do equivalente entre $10 \%$ e 50\% do valor expresso na Planilha de Preços de Referência do INCRA. A segunda modalidade trata das áreas ocupadas entre 2008 e 2011, de até 2.500 hectares. Nesse caso, deverá ocorrer o pagamento integral do preço da terra contido na Planilha de Preços de Referência do INCRA (que é menor que a metade do valor de mercado) (BRASIL, 2009). Em ambos os casos, há dispensa de licitação.

A previsão de pagamento pela regularização fundiária não torna o processo menos ilegítimo, até porque o não cumprimento do regimento tem sido prática recorrente. Em 2014, o Tribunal de Contas da União (TCU) realizou auditoria no Programa Terra Legal, criado em 2009 para operacionalizar a regularização fundiária na região da Amazônia Legal (Amazonas, Acre, Pará, Amapá, Roraima, Rondônia, Mato Grosso, Maranhão, Goiás e Tocantins). Nessa auditoria foi identificado que os preços pagos pela terra são irrisórios, ou seja, a grilagem compensa monetariamente.

O Programa Terra Legal, de 2009 a julho de 2014, cobrou pela terra, nos municípios da Amazônia Legal onde houve titulação de áreas superiores a 4 MF [módulos fiscais], valores irrisórios se comparados com os preços de mercado (utilizados como parâmetro em razão de se tratar de imóveis fora do âmbito da agricultura familiar), chegando a menos de $10 \%$ do valor de mercado em diversos municípios. [...] Como é o caso, dos municípios de Santa Luzia do Paruá (onde, este ano [2014], a partir da média de R \$954,56 da PPR [Planilha de Preço de Referência], o Terra Legal cobrou R \$ 82,52, em média) e Cuiabá/MT (onde, em 2012, a partir da média de R \$ 1.020,86 definida na PPR, o Terra Legal cobrou R \$234,30, em média). (TRIBUNAL DE CONTAS DA UNIÃO, 2014, p. 21).

Como se pode notar, além de a Planilha de Preços de Referência apresentar valores inferiores aos de mercado, a operacionalização da política de regularização fundiária beneficia os grileiros ao cobrar valores destoantes da planilha, rebaixando ainda mais o preço da terra grilada.

O impacto territorial decorrente de tal gestão, em que impera o favorecimento ao latifundiário, é de significativa envergadura, pois, embora numericamente as pequenas posses camponesas sejam a maioria dos beneficiados, em termos de área eles expressam a menor parte das regularizações fundiárias, sobressaindo-se as grandes propriedades. 
[...] a maioria (90\%) dos "ocupantes" das terras públicas são pequenos posseiros, o que é verdade. Porém, omite-se simplesmente que, à época, essa maioria ocupava apenas 19\% da área, e mais: que 5,96\% dos demais ocupantes grileiros concentravam o absurdo de 63\% da superfície a ser atingida pelo Programa Terra Legal. Ou seja, um programa hiperlegal para os latifundiários grileiros (OLIVEIRA, 2017, p. 19).

A regularização fundiária, no Brasil, se tornou um instrumento de acesso à terra por meio da legitimação da grilagem, na qual o patrimônio público passa para o domínio privado sem contrapartida ao conjunto da sociedade na mesma medida. Esse processo, embora histórico, não pode ser naturalizado. O PL 2.633/2020 não somente mantém essa trajetória histórica, como a amplia. Aliás, tão grande é a sede dos latifundiários em acessar as terras públicas não destinadas que a ampliação dos privilégios tem sido a regra desde a MP 422 de 2008.

Caso seja aprovado como está, esse projeto de lei manterá o limite temporal utilizado atualmente para regularização fundiária, ou seja, são passíveis de regularização áreas ocupadas até julho de 2008, considerando duas modalidades. A primeira se refere a estabelecimentos com até 06 módulos fiscais (em algumas regiões isso significa 660 hectares). Nesse caso haverá dispensa de licitação e o preço cobrado pela terra terá como base a Planilha de Preços de Referência do INCRA. No segundo caso, com estabelecimentos acima de seis módulos fiscais e até 2.500 hectares, deverá acontecer processo licitatório, embora o PL não expresse como isso irá ocorrer. Por isso, caberá ao governo, por meio de decreto, definir os critérios.

Deixar o estrato de área que abarca, historicamente, a maior parte das terras regularizadas a cargo de decreto presidencial é uma preocupação a ser considerada, pois a regra tem sido a entrega das terras aos latifundiários a preços irrisórios.

Ademais, o PL 2.633/2020 apresenta outras preocupações importantes que, embora não seja possível aprofundá-las nesse artigo, é necessário destacá-las. O PL tolera o desmatamento ilegal, ou, ao menos, não o combate, uma vez que permite que áreas já notificadas por desmatamento sejam regularizadas: basta que o grileiro faça o Termo de Ajustamento de Conduta (TAC), comprometendo-se em seguir a legislação ambiental. Nesses termos, o autor de crime ambiental não é responsabilizado, pelo contrário, poderá se tornar proprietário da terra.

A nova proposta de lei ainda destaca a dispensa de vistoria prévia para regularização fundiária em estabelecimentos de até 06 módulos fiscais e a dispensa de assinaturas dos confrontantes, já a comprovação da prática de cultura, exploração mansa e pacífica poderá acontecer por meio de sensoriamento remoto. Prerrogativas como essas fragilizam a política de regularização fundiária e podem ampliar o já expressivo conflito fundiário pelo país.

Inclusive, a título de informação adicional, segundo a Comissão Pastoral da Terra (CPT), o ano de 2019 foi marcado por um crescimento de $14 \%$ no número de assassinatos no campo em relação ao ano de 2018 , totalizando 32 assassinatos, sendo 07 lideranças indígenas vitimadas. (COMISSÃO PASTORAL DA TERRA, 2020).

Por fim, o PL 2.633/2020 prevê um verdadeiro prêmio os grileiros ao estender o prazo de renegociação para 2024 - na legislação atual o prazo é 2021. Postergar o prazo de renegociação das dívidas provenientes da regularização fundiária é beneficiar, exclusivamente, as médias e grandes propriedades, uma vez que os pequenos estabelecimentos, com até um módulo fiscal, podem ser regularizados gratuitamente por meio de legislação vigente.

O ano de 2020 termina com o pedido de urgência de tramitação desse PL na Câmara dos Deputados, mas sem caminhar efetivamente. Em função disso, o governo federal, por meio do INCRA, atualmente vinculado à Secretaria Especial de Assuntos Fundiários (SEAF), do Ministério da Agricultura, Pecuária e Abastecimento (MAPA), criou o Programa Titula Brasil em dezembro de 2020. O objetivo do programa é "aumentar a capacidade operacional dos procedimentos de titulação e regularização fundiária das áreas rurais sob domínio da União ou do Instituto Nacional de Colonização e Reforma Agrária" (SECRETARIA ESPECIAL DE ASSUNTOS FUNDIÁRIOS, 2020, p. 01). Trata-se, na prática, de transferir aos municípios a prerrogativa da regularização fundiária por meio da criação de um Núcleo Municipal de Regularização Fundiária (NMRF). Como os municípios são o lócus do clientelismo político, isto é, da troca de favores entre os membros da elite (MARTINS, 1994), isso conduzirá ao completo saque do patrimônio público pelos latifundiários locais, algo sem precedentes históricos.

As regras para esse processo estão na Instrução Normativa 105, publicada em janeiro de 2021, pelo INCRA, que, embora mantenha a exclusividade na emissão e na expedição de documentos titulatórios, bem como na definição das áreas passíveis de regularização fundiária, transfere aos municípios a coleta de 
requerimentos, declarações e documentos relacionados aos procedimentos de regularização fundiária, assim como as vistorias e o georreferenciamento. Dessa forma, ao INCRA cabe apenas o trabalho burocrático, documental, sem trabalho de campo e sem diálogo com a realidade material.

Em síntese, trata-se da terceirização dos municípios para regularização fundiária. Essa constatação evidencia o aprofundamento da política de regularização fundiária em benefício dos latifundiários, tornando cada vez mais legítimo o avanço sobre as terras públicas por meio da grilagem para, posteriormente, requerêlas para si. Por analogia, a verificação de Torres, Doblas e Alarcon (2017) parece pertinente para concluir essa análise: dono é quem desmata, dono é quem grila.

\begin{abstract}
"Dono é quem desmata", disse, em março de 2014, um grileiro de Novo Progresso (Pará), para justificar seu "direito" a espantosas extensões de terras públicas das quais - criminosamente - se apropriou e que terminou por desmatar. A máxima, além de sintetizar a articulação entre desmatamento, degradação ambiental e grilagem de terras públicas na Amazônia, acaba por revelar uma triste realidade: sim, quem desmata acaba dono (TORRES; DOBLAS; ALARCON, 2017, p. 01).
\end{abstract}

\title{
Considerações Finais
}

A análise das medidas adotadas pelo Estado demonstra que, ao longo do tempo, o acesso à terra por meio da regularização fundiária tem sido uma preocupação constante no Brasil. Governos diferentes, do ponto de vista partidário e político-ideológico, têm adotado medidas de impacto territorial semelhante. Em 2008, o ex-presidente Lula publicou a MP 442, possibilitando a regularização da grilagem de terra na Amazônia; em 2019, o atual presidente Bolsonaro publica medida parecida, a MP 910, ampliando a grilagem.

É nesse contexto de facilitação da regularização fundiária de terras apropriadas indiscriminadamente que o PL 2.633/2020 se insere, tendo como principal consequência a ampliação do latifúndio. Na mão contrária, as medidas de desconcentração fundiária e acesso à terra aos camponeses encolhem, sistematicamente, no mesmo período. A criação de assentamentos rurais começa a declinar em 2006, culminando na sua quase completa paralização em 2019, confirmando o abandono da reforma agrária pelo atual governo.

Cabe destacar, também, que as lutas camponesas apresentaram recuo nos últimos anos, dado que o número de ocupações e de famílias em ocupações de terras diminuiu drasticamente. Isso tem demonstrado que, na ausência de luta, a reforma agrária não segue na pauta pública.

Em síntese, esta pesquisa demonstrou que não há ambiguidade nas políticas fundiárias historicamente recentes, visto que se trata da prevalência da regularização do latifúndio, por meio da grilagem, em detrimento da reforma agrária, expressa na criação de assentamentos.

\section{Referências}

BRASIL. Câmara dos Deputados. Projeto de lei no 2633, de 14 de maio de 2020. Altera a Lei no 11.952, de 25 de junho de 2009, que dispõe sobre a regularização fundiária das ocupações incidentes em terras situadas em áreas da União; a Lei no 8.666, de 21 de junho de 1993, que institui normas para licitações e contratos da administração pública; a Lei no 6.015, de 31 de dezembro de 1973, que dispõe sobre os registros públicos; a fim de ampliar o alcance da regularização fundiária e dar outras providências. Brasília, DF, 14 maio 2020. Disponível em: https://www.camara.leg.br/proposicoesWeb/fichadetramitacao?idProposicao=2252589. Acesso em: 14 fev. 2021. BRASIL. Lei n ${ }^{\circ} 11.952$, de 25 de junho de 2009. Dispõe sobre a regularização fundiária das ocupações incidentes em terras situadas em áreas da União, no âmbito da Amazônia Legal; altera as Leis nos 8.666, de 21 de junho de 1993, e 6.015, de 31 de dezembro de 1973; e dá outras providências. Brasília, DF: Presidência da República, 2009. Disponível em: http://www.planalto.gov.br/ccivil_03/_ato20072010/2009/lei/111952.htm. Acesso em: 14 maio 2021.

BRASIL. Portal da Legislação. 2021. Disponível em: http://www4.planalto.gov.br/legislacao/. Acesso em: 14 fev. 2021.

BRITO, B. Nota técnica sobre o Projeto de Lei n. ${ }^{\circ}$ 2.633/2020. Belém: Imazon, 2020. Disponível em: https://imazon.org.br/publicacoes/ nota-tecnica-pl-2633-2020/. Acesso em: 14 fev. 2021.

CARVALHO, T. Bolsonaro: "MST pratica nada mais do que terrorismo". LeiaJa, [s. 1.], 28 jul. 2017. Disponível em: https://www. leiaja.com/politica/2017/07/28/bolsonaro-mst-pratica-nada-mais-do-que-terrorismo/. Acesso em: 12 fev. 2020. 
CERVO, A. L.; BERVIAN, P. A. Metodologia científica. 5. ed. São Paulo: Prentice Hall, 2002. COMISSÃO PASTORAL DA TERRA (CPT). Conflitos no campo: Brasil 2019. Goiânia: CPT Nacional, 2020.

CONSOLE, L. "MP da Grilagem atende aos que sempre se aproveitaram do país". Movimento dos Trabalhadores Rurais Sem Terra, 5 maio 2020. Disponível em: https://mst2.eita.coop.br/2020/05/05/mp-da-grilagem-atende-aos-que-sempre-se-aproveitaram-do-paisdiz-dirigente-do-mst/. Acesso em: 12 fev. 2021.

COSME, C. M. A burguesia latifundista não abre mão do monopólio da terra no Brasil: a perpetuação da concentração fundiária revelada pelo censo agropecuário 2017. Revista Pegada, v. 21, n. 1, 2020.

DANTAS, A. T.; JABBOUR, E. M. K.; SOBRAL, B. L. B. A recriação conservadora do Estado: impasses no reformismo progressista e popular e o golpe de 2016. Revista da ANPEGE, Grande Dourados, v. 10, n. 14, p. 5-38, jul./dez. 2016.

FELLET, J. Como a 'MP da grilagem' pode mudar o mapa de regiões da Amazônia. BBC NEWS, [São Paulo], 13 jan. 2020. Disponível em: https://www.bbc.com/portuguese/brasil-51071810. Acesso em: 12 fev. 2021.

FERNANDES, B. M. MST, formação e territorialização. São Paulo: Hucitec, 1996.

FERNANDES, B. M. Reforma agrária no governo Lula: a esperança. São Paulo: UNESP, 2003. Disponível em: http://www2.fct.unesp. br/nera/publicacoes/LULA_RA.pdf. Acesso em: 14 fev. 2021.

INSTITUTO BRASILEIRO DE GEOGRAFIA E ESTATÍSTICA (IBGE). Censo Agropecuário 2017. Disponível em: https://sidra. ibge.gov.br/pesquisa/censo-agropecuario/censo-agropecuario-2017. Acesso em: 15 jan. 2021.

LACOSTE, Y. A geografia: isso serve, em primeiro lugar para fazer a guerra. São Paulo: Papirus, 1988.

MARÉS, C. F. A função social da terra. Porto Alegre: Safe, 2003.

MARTINS, J. S. O Cativeiro da Terra. 9. ed. São Paulo: Contexto, 2010.

MARTINS, J. S. O poder do atraso: ensaios de sociologia da história lenta. São Paulo: Hucitec, 1994.

MOTTA, M. M. M. A grilagem como legado. In: MOTTA, M. M. M.; PIÑEIRO, T. L. Voluntariado e universo rural. Rio de Janeiro: Vício de Leitura, 2002. p.77-101.

NÚCLEO DE ESTUDOS, PESQUISAS E PROJETOS DE REFORMA AGRÁRIA (NERA). Relatório DATALUTA Brasil. Presidente Prudente: NERA, n. 20, 2020.

OLIVEIRA, A. U. A geografia das lutas no campo. São Paulo: Contexto, 1988.

OLIVEIRA, A. U. Grilagem de terras: a raposa e o galinheiro. Le Monde Diplomatique Brasil, São Paulo, ed. 20, 05 mar. 2009. Disponível em: https://diplomatique.org.br/a-raposa-e-o-galinheiro/. Acesso em: 14 fev. 2021.

OLIVEIRA, A. U. Modo de Produção Capitalista, Agricultura e Reforma Agrária. São Paulo: Labur, 2007.

OLIVEIRA, A. U. Prefácio. In: TORRES, M.; DOBLAS, J.; ALARCON, D. F. Dono é quem desmata: conexões entre grilagem e desmatamento no sudoeste paraense. São Paulo: Urutu-branco; Altamira: Instituto Agronômico da Amazônia, 2017.

PAULINO, E. T. Estrutura fundiária e dinâmica socioterritorial no campo brasileiro. Mercator, Fortaleza, v. 10, n. 23, p. 111-128, set./dez., 2011.

SECRETARIA ESPECIAL DE ASSUNTOS FUNDIÁRIOS (SEAF). Portaria Conjunta $n^{\circ} 1$, de 2 de dezembro de 2020. Disponível em: https://www.in.gov.br/en/web/dou/-/portaria-conjunta-n-1-de-2-de-dezembro-de-2020-291801586. Acesso em: 14 fev. 2021.

SILVA, L. O. Terras devolutas e latifúndio: efeitos da lei de 1850. 2. ed. Campinas: Unicamp, 2008.

TORRES, M; DOBLAS, J; ALARCON, D. F. Dono é quem desmata: conexões entre grilagem e desmatamento no sudoeste paraense. São Paulo: Urutu-branco; Altamira: Instituto Agronômico da Amazônia, 2017.

TRIBUNAL DE CONTAS DA UNIÃO (TCU). Relatório de auditoria de conformidade no programa Terra Legal Amazônia. Processo 015.859/20142. 2014. Disponível em: https://pesquisa.apps.tcu.gov.br/\#/documento/processo/*/NUMEROSOMENTENUMEROS\%253A1585920142/ DTAUTUACAOORDENACAO\%2520desc\%252C\%2520NUMEROCOMZEROS\%2520desc/0/\%2520. Acesso em: 14 fev. 2021.

\section{Notas}

Até 1920, somente $20 \%$ da superfície territorial estava ocupada por estabelecimentos rurais (SILVA, 2008, p. 84).

2 Em 2017, quando ainda era deputado federal, o atual presidente fez a seguinte afirmação aos eleitores: "O MST nunca levou tanto terror ao campo. Nós devemos criminalizar esse movimento". (CARVALHO, 2017).

3 A dimensão do módulo fiscal é variável no Brasil e pode chegar a 110 hectares em alguns municípios.

4 "Como a 'MP da grilagem' pode mudar o mapa de regiões da Amazônia" (FELLET, 2020). "MP da Grilagem atende aos que sempre se aproveitaram do país". (CONSOLE, 2020). 
Fábio Luiz Zeneratti

fabio.zeneratti@uffs.edu.br

Doutor em Geografia pela Universidade Estadual de Londrina (UEL).

Professor Adjunto da Universidade Federal da Fronteira Sul, campus Laranjeiras do Sul (UFFS)

\section{UFFS}

BR 158 - Km 405 - Zona Rural.

Laranjeiras do Sul, Paraná, Brasil.

CEP. 85.301-970.

\section{Agradecimentos}

Não se aplica.

Agência financiadora

Não se aplica.

Contribuições dos autores

$\mathrm{O}$ artigo foi elaborado em todas as partes pelo autor.
Aprovação por Comitê de Ética

Não se aplica.

Consentimento para publicação

Consentimento do autor.

Conflito de interesses

Não há conflito de interesses. 